\title{
Design of A Roadmap for Implementing A Quality Approach At ONS-Algeria
}

\author{
Tarik Bourezgue* \\ Office National des Statistiques, Algeria
}

Submission: April 19, 2018; Published: July 10, 2018

*Corresponding author: Tarik Bourezgue, Office National des Statistiques, Algiers, Algeria; Email: tarikbourezgue@gmail.com

\begin{abstract}
The rapid changes in Algeria have had and continue to have a profound impact on infrastructure, economic agents and the population as a whole. These transformations have already turned the statistical landscape upside down and will continue to do so. In fact, the need for statistical data has changed and evolved in terms of the nature of the statistics, on one hand, and requirements regarding availability, quality and time, on the other hand. Starting from the context described above, the development of ONS-Algeria's quality approach is essentially based on the capitalization of the work of cooperation with Eurostat on the principles of the European Quality Assurance Framework for Official Statistics (QAF), the option for a participatory and transparent process to enrich this approach and facilitate its appropriation and lastly, conducting the process in stages. In driving the process step by step, to optimize its management, our paper will address the issues related to the design of a roadmap for implementing the Code of Practice (CoP) for the ENP south countries.
\end{abstract}

Keywords: Code of practice; Implementation challenges; Quality management; ENP South countries

Abbreviations: QAF: Quality Assurance Framework for Official Statistics; Code of Practice; GSBPM: General Statistical Model of The Operational Process; METIS: Statistical Metadata; SAQ: Self-Assessment Questionnaire; CPI: Consumer Price Index

\section{Introduction}

The rapid changes in the country have had and continue to have a profound impact on infrastructure, economic agents and the population as a whole. These transformations have already turned the statistical landscape upside down and will continue to do so. In fact, the need for statistical data has changed and evolved in terms of the nature of the statistics, on one hand, and requirements regarding availability, quality and time, on the other hand [1-3]. Starting from the context described above, the development of our quality approach is essentially based on the following three principles:

a. The capitalization of cooperation initiatives with Eurostat on the principles of the European Quality Assurance Framework for Official Statistics (QAF);

b. The choice of a participatory and transparent process to enrich this approach and facilitate our making it our own;

c. And lastly, conducting the process step by step, in order to optimize its steering.

\section{Approach}

It should be noted that ONS takes into account quality guidelines in the performance of its processes according to international standards. Indeed, ONS participates in the work of the South Mediterranean Quality Working Group and contributed to the development of the Regional Code of Practice (CoP) (ENPSouth) [4].

In tandem with the "classical" quality approach, which requires rapid and intense mobilization of resources, and referring to the QAF guidelines, the quality approach adopted by ONS, based on the CoP, is a step-by-step and progressive quality approach. It is organized around four levels of a step by step implementation:

\section{Recurring surveys \\ II. Structural surveys \\ III. Major operations such as census \\ IV. The institution}

As each survey phase is a potential source of errors, it is necessary to analyze the different processes within each phase, to determine the errors and to find the methods to eliminate them or to reduce them.

Even though ONS applies control actions in carrying out these surveys, a well-defined quality control system is needed and is part of the projects carried out by the quality unit. In fact, the control actions to be integrated into the production process to improve the quality of the data are: 
a. Preventive control actions are put to practice to prevent errors from being verified: we act on the sources of errors.

b. Ongoing control actions are applied to monitor and correct errors while performing a survey. One can find tools and methods to identify errors when they are verified and to limit their effects on the survey results.

c. A posteriori evaluation actions are those operations that make it possible to measure errors directly or indirectly, and in particular control surveys carried out after data collection.

Therefore, all of these control actions represent the quality control system of a survey. For this reason, when designing and conducting a survey, part of the budget must be reserved for data quality control actions.

In addition, the use of the general statistical model of the operational process (GSBPM), developed by the UNECE/ Eurostat/OECD working group on Statistical Metadata (METIS), to document our statistical operations. Indeed, the GSBPM has been developed to provide a standard framework for the operational processes required to produce official statistics. The GBSPM can also be used to integrate standards relating to data and metadata, as a model for process documentation for the harmonization of statistical IT infrastructure, and to provide a framework for assessing and improving the quality of data: it is a representation model of the statistical process. Quality being considered as an overarching process, this model highlights the principle that quality must be integrated at every stage, combined with the notion that quality is multidimensional. Hence, this model is defined by the aspects related, on the one hand, to the quality of the statistical data (relevance, accuracy, etc.) and, on the other hand, to the quality of the process (precision of needs, design, implementation, execution and evaluation) [5,6].

\section{Implementation}

In order to ensure that the implementation, of the quality approach at ONS, is rigorous; we base its framework on the following manuals:

i. Quality Assurance Framework (QAF): defining the principles of the quality system.

ii. Code of Practice (CoP): defining the indicators measuring the implementation of the quality system.

iii. The Self-Assessment Questionnaire (SAQ): measuring the implementation of the quality system at two levels:

- Institutional

- $\quad$ Process.

Table 1: Time table.

\begin{tabular}{|c|c|c|c|c|c|c|c|}
\hline & \multicolumn{2}{|c|}{$\begin{array}{c}\text { Dec- } \\
15\end{array}$} & 2016 & 2017 & $2017 / 2018$ & $\begin{array}{c}\text { End } \\
2019\end{array}$ & 2020 \\
\hline Action $N^{\circ}$ & 1 & 2 & 3 & 4 & 5 & 6 & 7 \\
\hline
\end{tabular}

To achieve these objectives, the stages/actions of the gradual implementation of our quality approach could be broken down as follows (Table 1):

i. A clear display (website, notes to the technical and regional departments) of the Commitment on Quality by Top Management.

ii. The designation of the technical staff assigned to the unit in charge of quality support and communication with the technical departments.

iii. The presentation of quality tools and related documentation by the Quality Unit, under the control and with the support of Top Management, to the technical departments.

iv. The implementation of the GSBPM to document the collection processes for the Consumer Price Index (CPI) and the labor force surveys, and other surveys deemed appropriate by Top Management.

v. The implementation of the SAQ by the structures that applied the GSBPM.

vi. The implementation of the GSBPM and SAQ for the population census.

vii. A self-evaluation process through the implementation of the SAQ by the institution.

\section{Conclusion}

We should note that executives tend to have a relatively rosy view of how well-defined their culture is and how nicely it is performing. Those in quality management who are closer to where the rubber meets the road have a dimmer view. Without consensus on what's broken and how bad it is, there will be disagreement on what to fix. Such discoveries shouldn't be news to anyone who has lead or is aspiring to achieve a strong and sustainable culture of quality excellence.

Hence, at ONS we are aware that it would be especially helpful if suggestions were woven together to answer at least a few important questions and improve our approach:

a. Are there any details missing in the approach that must be understood for a successful culture of quality?

b. Because understanding users is critical to guiding success, is there some intuitive framework or method accessible to management and quality practitioners alike?

c. Is there a quick, easy, and practical way to determine how well top management and the rest of the organization agrees on the cultural characteristics of excellence?

d. Would such a cultural assessment be enough to inspire consensus for action?

Furthermore, from the first stages of implementation, three guidelines that rise to the top and are strongly related to each other: 
I. All employees must apply the key elements of any strategy for building a quality culture.

II. Closely understand user expectations so we can focus and give them what they want.

III. Develop a formal quality policy, common language, and leader behaviors as deployment mechanisms.

We do understand that changing our culture to integrate quality excellence is not an easy process. We'll have good days and bad days, progress and setbacks. We have to keep going when change is hard as we are inspired by this Henry Ford's quote:
"One of the greatest discoveries a man makes, one of his great surprises, is to find he can do what he was afraid he couldn't do."

\section{References}

1. Eurostat (2015) Quality Assurance Framework, QAF V1.2.

2. Eurostat (2011) European Statistics Code of Practice.

3. (2015) Statistics Code of Practice for the European Neighborhood South countries.

4. (2013) The Generic Statistical Business Process Model.

5. (2013) The Generic Statistical Information Model, (GSIM V 1.1).

6. (2009) The Common Metadata Framework.

\section{Your next submission with Juniper Publishers} will reach you the below assets

- Quality Editorial service

- Swift Peer Review

- Reprints availability

- E-prints Service

- Manuscript Podcast for convenient understanding

- Global attainment for your research

- Manuscript accessibility in different formats ( Pdf, E-pub, Full Text, Audio)

- Unceasing customer service

Track the below URL for one-step submission https://juniperpublishers.com/online-submission.php 